\title{
Determinação do fator de correção das hortaliças folhosas comercializadas em Brasília
}

\author{
Aline G Lemos' ${ }^{1}$; Raquel BA Botelho²; Rita de Cássia CA Akutsu² \\ ${ }^{1}$ UnB, Centro Excelência em Turismo, Campus Darcy Ribeiro s/n, 70910-000 Brasília-DF, aline_sl@bol.com.br; ${ }^{2}$ UnB, Depto. Nutrição, \\ raquelbotelho@terra.com.br; rita_akutsu@yahoo.com.br
}

\begin{abstract}
RESUMO
O Brasil tem índices elevados de desperdício de alimentos, fato que afeta a economia e acentua os problemas sociais. O planejamento inadequado do processamento de alimentos, desde a pós-colheita até o consumo, é um dos canais do desperdício. As hortaliças têm sua durabilidade afetada por serem passíveis de sofrer modificações inerentes aos processos de crescimento e de maturação e por passarem por práticas higienizadoras e por serem submetidas a operações de subdivisão e/ou de cocção. Para tentar minimizar as perdas, a determinação do Fator de Correção (FC) de hortaliças é essencial, pois, este pode propiciar uma avaliação mais precisa do grau de desperdício e quais os fatores que podem intervir nas perdas. Este trabalho consiste na determinação de FC das seguintes hortaliças folhosas: alface americana, alface crespa, alface lisa, alface roxa, acelga, almeirão, agrião, chicória, couve manteiga, escarola, espinafre, mostarda, repolho branco, repolho roxo e rúcula. Foram adquiridas unidades de venda (no atacado) de cada hortaliça na Central de Abastecimento (CEASA) de Brasília-DF, de três fornecedores diferentes, em diferentes meses de colheita (abril, maio junho e outubro), perfazendo 36 amostras por hortaliça. Com o objetivo de detectar se existe influência dos meses de colheita sobre os fatores de correção parcial (FC 1) e final (FC 2), empregou-se a análise de variância e o teste de Tuckey para comparação das médias, ao nível de 5\% de significância Os resultados apontaram que, para a maioria das hortaliças, não houve influência dos meses de colheita sobre o desperdício, considerando-se que não houve diferença estatística significativa entre os dados. No entanto para a acelga, a escarola e o repolho branco foram detectadas diferenças significativas. Para a acelga, o menor FC (ou seja, o menor desperdício) ocorreu na entressafra; já para o repolho branco, o menor FC ocorreu na safra. Assim, de modo geral, as perdas avaliadas pelo FC estão mais relacionadas ao manipulador das folhosas e ao estado de conservação das hortaliças do que ao período de safra. Desta forma, para as hortaliças que apresentaram diferenças com relação à época de amostragem, recomenda-se observância quanto ao período de planejamento dos cardápios visando a obtenção do aproveitamento eficiente do produto.
\end{abstract}

Palavras-chave: perdas, safra de hortaliças, desperdício.

\begin{abstract}
Correction factor determination in leafy vegetable crops commercialized in Brasilia, Brazil

Brazil has high indexes of food waste, which affects regional economy and increases social problems. Inadequate planning of food processing, from postharvest to consumption, is one of the reasons of loss. Vegetable crops are live organisms and their durability is affected by the processes of subdivision and cooking. To reduce losses, the determination of the Correction Factor is essential in order to evaluate the losses and the factors which interfere on these losses. This work consists on determining the Correction Factor of the following vegetable crops: Crisphead Lettuce, Unheaded Lettuce, Lettuce, Purple Leafs, Chard, Endive, Watercress, Common Chicory, Borecole Green Collard, Escarole, Spinach, Mustard, Cabbage, Red Cabbage and Rocket Crop. Three sale units of each vegetable crop were acquired at the CEASA in Brasília (Federal District, Brazil), from three different suppliers, with four replicates, a total of 36 samples of each vegetable crop. Aiming to detect the influence of the gathering month on the Partial Correction Factor (CF 1) and Final Correction Factor (CF 2) analysis of variance (ANOVA) and Tukey test were carried out. In all tests a level of $5 \%$ of statistical significance was considered. The results showed that for the majority of the vegetables, harvest does not influence loss. However for chard, the lower CF occurred at harvest. On the other hand for cabbage, the lower CF occurred at harvest. This way for the majority of the vegetables, the losses evaluated by the $\mathrm{CF}$ are more related to handling procedures and conservation. For cabbage, it is recommended not to include it on meals in the harvest period because the vegetable is more expensive and losses are higher. Therefore, for vegetables that are influenced by harvest, it is recommended to observe the best period for menu planning.
\end{abstract}

Keywords: waste, harvest, losses.

(Recebido para publicação em 16 de abril de 2010; aceito em 29 de abril de 2011)

(Received on April 16, 2010; accepted on April 29, 2011)

$\mathrm{O}$ vegetais foram os primeiros alimentos do homem. A palavra vegetal originou-se do verbo em latim vegere, que significa revigorar. As hortaliças compreendem as partes co- mestíveis das plantas: raízes tuberosas, tubérculos, caules, folhas, flores, frutos e sementes. Popularmente são conhecidas como verduras e legumes e têm papel importante na mesa do brasileiro por serem fontes de fibras, vitaminas e minerais (Araújo et al., 2007).

Em virtude da diversidade de conceitos acerca da nomenclatura das partes comestíveis, este estudo adota a 
definição de hortaliça, segundo a Agência Nacional de Vigilância Sanitária (ANVISA) (Brasil, 2008a): "Hortaliça é a planta herbácea da qual uma ou mais partes são utilizadas como alimento na sua forma natural". Assim, o termo hortaliça designa de forma genérica às plantas herbáceas empregadas na alimentação humana.

Segundo Vilela et al. (2003a) no Brasil, as perdas começam na colheita continuando no transporte, na comercialização, prosseguindo até os consumidores intermediários e finais. Dessa forma, o desperdício parece fazer parte da cultura brasileira e, portanto, difícil de ser alterado, podendo afetar a produção do País e resultar em perdas significativas. Apenas o desperdício de alimentos gera prejuízos equivalentes a $1,4 \%$ do PIB nacional (Perone, 2004).

As perdas em hortaliças, desde o momento da colheita até a mesa do consumidor, são da ordem de 35 a 45\% (Vilela et al., 2003a; Vilela et al., 2003b). Contudo, tecnologias podem ser empregadas na fase de pós-colheita visando diminuir as perdas e manter a qualidade do produto, como por exemplo, o uso de embalagens que preservem as características do vegetal, a paletização da carga, a utilização de câmaras frias, o transporte e a armazenagem apropriados (Brasil, 2004).

A pós-colheita exerce papel essencial no atendimento às expectativas dos consumidores com relação à qualidade do produto final, pois é nesta etapa que acontecem os processos de classificação, embalagem, manuseio e transporte, que devem ser adequados à cadeia produtiva. A não-condução desses processos de maneira adquada e também de práticas como a colheita precoce, na tentativa de aumentar a resistência do vegetal ao transporte, podem causar a depreciação na qualidade do produto (IEA, 2008).

Segundo a Companhia de Entrepostos e Armazéns Gerais de São Paulo (CEAGESP) (Brasil, 2008b), o desperdício de hortaliças, da pós-colheita até o consumo, varia de acordo com o processo ao qual o vegetal é submetido. Logo após a colheita, muitas hortaliças podem ser total ou parcialmente descartadas devido ao seu grau de maturação, a defeitos que tornem indesejáveis sua aceitação no mercado ou a deformações estéticas em folhas. Caso o produto seja lavado antes do processamento, deve ser seco em seguida, pois a umidade poderá propiciar o apodrecimento e a contaminação da hortaliça, e consequentemente, sua inviabilidade para o consumo.

A perda de alimentos é uma questão importantíssima para a gestão de uma Unidade de Alimentação e Nutrição (UAN), definido como subsistema que desempenha atividades fins ou meios, as quais contemplam o planejamento e a elaboração de refeições equilibradas, nutritivas, salubres e seguras da perspectiva de higiene, visando auxiliar o desenvolvimento de hábitos alimentares saudáveis (Lanzellotti et al., 2004; Proença et al., 2005). Dessa maneira, a padronização de processos por meio da criação de rotinas e de procedimentos técnicos operacionais, de treinamento da equipe e de controle das atividades por meio de análises, deve ser levada em consideração para que perdas não ocorram durante o processamento (Hirschbruch, 1998).

Para melhor atender a este planejamento, Akutsu et al. (2005) e Costa et al. (2010) citam a importância de ferramentas que podem auxiliar no processo de produção de refeições, como por exemplo, a Ficha Técnica de Preparação (FTP), que contem indicadores per capita, fator de correção e de cocção, composição centesimal em macro e micronutrientes da preparação, rendimento e número de porções.

$\mathrm{O}$ indicador de desperdício chamado Fator de Correção (FC) é definido como a relação entre o peso do alimento bruto, ou seja, na forma como foi adquirido, com cascas, talos, sementes, e o peso do alimento líquido, após passar por processo de limpeza. É um indicador que determina a quantidade exata de alimento que será descartada e que deve ser empregado no planejamento quantitativo de um cardápio e consequentemente, no seu valor nutricional. Deve-se considerar que o FC das hortaliças depende do manipulador, dos utensílios e dos equipamentos utilizados no processamento, do tipo de produto, da qualidade, do grau de amadurecimento e da safra (Botelho \& Camargo, 2005).

Para o processamento das hortali- ças, removem-se, inicialmente, folhas velhas, talos endurecidos, partes deterioradas, cascas, etc., que representam, a exemplo do milho verde, uma perda do peso inicial de até $62 \%$ (Ornellas, 2006).

Devido ao número elevado de refeições que utilizam hortaliças no seu preparo e também a sua importância para a saúde humana, faz-se necessária a realização de estudos que avaliem o fator de correção para se estipular com precisão as perdas que ocorrem nos processos de higienização, manipulação e seleção desses alimentos.

Este trabalho teve como objetivo determinar as perdas que ocorrem em hortaliças quando da produção de refeições, empregando-se o indicador Fator de Correção em 15 espécies de hortaliças folhosas comercializadas em Brasília-DF.

\section{MATERIAL E MÉTODOS}

Amostras para este estudo foram adquiridas na Central de Abastecimento S.A.(CEASA) de Brasília-DF, em virtude de ser este o local de compra do tipo de usuários considerados neste trabalho. Para a aquisição das amostras, foram realizadas quatro visitas ao local, nos meses de abril, maio, junho e outubro para compra das hortaliças folhosas compreendendo o período de safra e entressafra.

As hortaliças inventariadas nesta pesquisa foram: alface americana, alface crespa, alface lisa e alface roxa (todas Lactuca sativa L.), acelga (Beta vulgaris cicla), almeirão (Cichorium intybus L), agrião (Nasturtium officinale R. Br.), chicória (Cichorium endivia L.), couve manteiga (Brassica oleracea L. var. acephala), escarola (Beta vulgaris L. var. cicla), espinafre (Spinacea oleracea L.), mostarda (Sinapis arvensis L), repolho branco (Brassica oleracea $L$. var. capitata), repolho roxo (Brassica oleracea L. var. capitata) e rúcula (Eruca sativa L).

Foram adquiridas três unidades de venda no atacado de cada hortaliça, de três fornecedores diferentes, considerando-se ainda safra e entressafra (meses de abril, maio junho e outubro), perfazendo 36 amostras por hortaliça. No momento 
da aquisição, um único pesquisador adquiriu os produtos em cada fornecedor sem informá-lo do objetivo da compra.

O período de safra das folhosas estudadas é variável, sendo para alface de abril a setembro; para a acelga e o agrião, entre julho e novembro; para o almeirão, de julho a outubro; para a couve compreende o mês de janeiro e o intervalo de junho a outubro; para a chicória e o espinafre este período vai de julho a outubro; para a escarola compreende os meses de janeiro e o intervalo de julho a outubro; para a mostarda vai de julho até dezembro; para o repolho branco e o repolho roxo o intervalo compreende os meses de maio a setembro e para a rúcula compreende de maio a outubro.

Na determinação do Fator de Correção (FC) foi utilizada a fórmula desenvolvida por Araújo et al. (2007), que calcula a relação entre o peso do alimento como adquirido (Peso Bruto, $\mathrm{PB})$ e o peso do alimento após a limpeza (Peso Líquido, $\mathrm{PL})(\mathrm{FC}=\mathrm{PB} / \mathrm{PL})$. Dessa maneira, foi determinado o Fator de Correção parcial (FC1). Para a sua obtenção foram retiradas das hortaliças as folhas danificadas, as raízes e os talos centrais, habitualmente retirados nos restaurantes. Ou seja, o peso integral das hortaliças foi considerado como PB e após a limpeza, obteve-se o PL.

A limpeza foi realizada segundo o tipo de hortaliça considerada. Para a acelga e o agrião foram retiradas as folhas danificadas e o talo inferior e central, respectivamente. No caso do almeirão, chicória e escarola foram eliminadas apenas as folhas danificadas; para a couve, o espinafre e a mostarda foram retiradas as folhas danificadas e o talo central; para o repolho branco e o repolho roxo foram descartadas as folhas danificadas e o centro da hortaliça; para a rúcula foram eliminadas as folhas danificadas e as raízes.

$\mathrm{Na}$ obtenção do Fator de Correção Final (FC2), foram retiradas e pesadas as partes que não são habitualmente descartadas das hortaliças, como por exemplo, os talos laterais do agrião deixando somente as folhas. Para a acelga foi retirado o centro que corresponde ao talo; no caso do espinafre foram retirados os talos das folhas; para a rúcula foram retiradas as nervuras. Para o FC2, a fórmula utilizada calcula a relação entre o peso do alimento como adquirido (Peso Bruto, PB) e o peso do alimento após a limpeza completa (PL2) itens citados para o FC1 e o FC2 (FC2= PB/PL2).

As pesagens foram realizadas no Laboratório de Técnica Dietética da Universidade de Brasília, em balança (Marte® modelo AS 2000) com capacidade carga máxima de 2 kg e carga mínima de 0,25 g, com precisão de 0,05 g.

Os dados dos FCs (FC1 e FC2) foram utilizados para o cálculo da média, do desvio padrão e do coeficiente de variação $(\mathrm{CV})$ com o programa Microsoft Excel $^{\circledR}$.

Para analisar o coeficiente de variação (CV) foi utilizada a classificação de Gomes (2000). Valores de CV inferiores a 10\% foram considerados baixos; de $10 \%$ a $20 \%$, médios; de $20 \%$ a $30 \%$ alto e acima de $30 \%$ muito alto.

As hipóteses do estudo foram testadas por meio da análise de variância (ANOVA). Foi adotado o nível de significância $\mathrm{p}<0,05$ para os testes, indicando que as diferenças identificadas entre as médias dos grupos têm uma probabilidade de $95 \%$ de ocorrer devido ao período de colheita e apenas $5 \%$ de acontecer ao acaso. Todos os testes realizados foram precedidos pelo exame da normalidade de distribuição da amostra e o teste de homogeneidade de variância de Levene (Hair et al., 2009), os quais indicaram que a matriz dos dados atende aos pressupostos dessa técnica estatística.

O teste de Turkey foi utilizado para comparação das médias mensais. Fixou-se, para todos os testes, o nível de significância de $5 \%(\mathrm{p}<0,05)$.

\section{RESULTADOS E DISCUSSÃO}

Considerando o peso médio de cada hortaliça, observou-se coeficientes de variação elevados (de 2,1\% a 66,6\%) que ocorreram devido às diferenças entre os pesos das 36 amostras por hortaliça analisadas (Tabela 1). Os maiores coeficientes de variação ocorreram para alface americana $(\mathrm{CV}=54,2 \%)$, alface crespa $(\mathrm{CV}=66,6 \%)$, e repolho branco $(\mathrm{CV}=35,4 \%)$, em período de entressafra e para a acelga $(\mathrm{CV}=43,9 \%)$, na safra. Essa diferença de peso entre os produtos obtidos em períodos de safra e de entressafra deve ser considerada no planejamento de cardápios em restaurantes que atendem as diversas populações como na esfera doméstica. Como as folhosas são adquiridas por unidade e não por peso, o consumidor pode não perceber essa diferença de gramatura explicitada nos coeficientes de variação (CV) o que pode conduzir a sobras ou falta de hortaliças nas refeições planejadas. É importante salientar que os altos valores do CV também podem ter ocorrido em virtude do número reduzido de amostras consideradas neste estudo.

A Tabela 2 apresenta os FC1s determinados a cada mês de coleta de amostras para as diversas hortaliças. Observou-se que não houve influência de época de colheita sobre o FC1 da alface americana, alface lisa, alface crespa, agrião, almeirão, couve, chicória, espinafre, mostarda e repolho roxo. Essa uniformidade facilita o treinamento de funcionários que manipulam hortaliças. O nutricionista poderá esperar FCs similares ao longo do ano, podendo prever os desperdícios e diminuindo restos (parte inaproveitável dos alimentos) (Araujo et al., 2007) da produção de refeições. Este controle permite reduzir os custos na elaboração das refeições. Os resultados obtidos indicam que o período de colheita dessas hortaliças não influenciou o desperdício por ocasião do seu processamento.

Para a acelga, a escarola e o repolho branco, os dados de FC1 indicaram que há diferenças significativas $(\mathrm{p}<0,05)$ relacionadas às perdas para a época de colheita. Para a acelga, a diferença do índice de desperdício entre as épocas de colheita foi de $62,5 \%$. Essa hortaliça apresentou padrão similar para o FC2, com média de 1,16 para a entressafra e de 1,79 na safra, sendo essa diferença considerada significativa $(\mathrm{p}<0,05)$.

Para o repolho branco, o menor desperdício (12\%) no processamento ocorreu na safra do que na entressafra (19\%). Para a escarola, a variação de desperdício foi de 38,5\% nos períodos de colheita, sendo menor na safra.

Em relação ao $\mathrm{FC} 2$, os resultados indicam que, para a rúcula, o FC2 foi 
Tabela 1. Medidas de tendência central e dispersão de 15 hortaliças comercializadas na Ceasa de Brasília (central trend and dispersion measures of sale vegetable crops sold at the CEASA in Brasilia, Federal District, Brazil). Brasília, UnB, 2009.

\begin{tabular}{|c|c|c|c|c|c|c|c|c|c|c|c|c|}
\hline \multirow[b]{2}{*}{ Hortaliças } & \multicolumn{3}{|c|}{ Abril } & \multicolumn{3}{|c|}{ Maio } & \multicolumn{3}{|c|}{ Junho } & \multicolumn{3}{|c|}{ Outubro } \\
\hline & $\begin{array}{c}\text { Média } \\
\text { (g) }\end{array}$ & $\begin{array}{c}\text { DP* } \\
(\mathrm{g})\end{array}$ & $\begin{array}{c}C V^{* *} \\
(\%)\end{array}$ & $\begin{array}{c}\text { Média } \\
\text { (g) }\end{array}$ & $\begin{array}{c}\text { DP* } \\
(\mathrm{g})\end{array}$ & $\begin{array}{c}C V^{* * *} \\
(\%)\end{array}$ & $\begin{array}{c}\text { Média } \\
\text { (g) }\end{array}$ & $\begin{array}{c}\text { DP* } \\
(\mathrm{g})\end{array}$ & $\begin{array}{c}C V^{* * *} \\
(\%)\end{array}$ & $\begin{array}{c}\text { Média } \\
\text { (g) }\end{array}$ & $\begin{array}{c}\text { DP* } \\
(\mathrm{g})\end{array}$ & $\begin{array}{c}C V^{* *} \\
(\%)\end{array}$ \\
\hline Alface americana & 305,1 & 67,4 & 22,1 & 370,8 & 75,8 & 20,4 & 496,4 & 87,8 & 17,7 & 490,2 & 265,7 & 54,2 \\
\hline Alface roxa & 204,6 & 73,3 & 35,8 & 207,7 & 85,2 & 41,0 & 138,7 & 12,8 & 9,0 & 180,1 & 44,0 & 24,4 \\
\hline Alface lisa & 208,4 & 21,8 & 10,5 & 261,7 & 36,0 & 13,7 & 313,5 & 58,8 & 18,7 & 206,1 & 38,7 & 18,8 \\
\hline Alface crespa & 157,0 & 4,7 & 3,0 & 205,3 & 42,5 & 20,7 & 213,2 & 37,8 & 17,7 & 285,3 & 190,0 & 66,6 \\
\hline Acelga & 1223,6 & 443,3 & 36,2 & 1086,4 & 110,7 & 10,2 & 1154,9 & 329,8 & 28,5 & 2042,9 & 897,0 & 43,9 \\
\hline Agrião & 457,4 & 36,5 & 8,0 & 485,8 & 24,9 & 5,1 & 470,3 & 10,7 & 2,3 & 513,7 & 77,0 & 15,0 \\
\hline Almeirão & 272,6 & 93,4 & 34,3 & 266,2 & 33,2 & 12,5 & 242,2 & 53,3 & 22,0 & 241,1 & 95,7 & 39,7 \\
\hline Couve & 432,6 & 9,0 & 2,1 & 407,4 & 38,5 & & 378,2 & 13,9 & 3,7 & 467,9 & 100,8 & 21,5 \\
\hline Chicória & 242,5 & 12,2 & 5,0 & 266,6 & 32,0 & 12,0 & 281,2 & 92,6 & 32,9 & 543,6 & 65,4 & 12,0 \\
\hline Espinafre & 410,6 & 124,8 & 30,4 & 590,8 & 57,7 & & 706,9 & 137,4 & 19,4 & 555,6 & 110,5 & 19,9 \\
\hline Escarola & 241,1 & 33,4 & 13,9 & 234,4 & 33,9 & 14,5 & 254,4 & 58,8 & 23,1 & 289,3 & 46,2 & 16,0 \\
\hline Mostarda & 357,7 & 54,3 & 15,2 & 382,6 & 157,9 & 41,3 & 496,1 & 180,1 & 36,3 & 443,0 & 84,8 & 19,2 \\
\hline Repolho branco & 981,7 & 154,0 & 15,7 & 1087,6 & 93,7 & 8,6 & 1400,1 & 225,8 & 16,1 & 2074,9 & 734,6 & 35,4 \\
\hline Repolho roxo & 1114,7 & 225,7 & 20,2 & 1217,0 & 210,2 & 17,3 & 1361,9 & 377,0 & 27,7 & 1660,4 & 301,3 & 18,1 \\
\hline Rúcula & 194,3 & 23,7 & 12,2 & 257,3 & 52,9 & 20,2 & 272,9 & 54,3 & 19,9 & 238,9 & 21,7 & 9,1 \\
\hline
\end{tabular}

*Desvio padrão; ${ }^{*} \mathrm{CV}=$ Coeficiente de variação $(* \mathrm{SE}=$ Standard Error; $* * \mathrm{CV}=$ Coefficient of variation).

Tabela 2. Efeito dos meses de coleta sobre o Fator de Correção Inicial (FC1) de 15 hortaliças coletadas na Ceasa de Brasília (effects of month on the Initial Correction Factor (FC1) of 15 vegetable crops collected at the CEASA in Brasilia, Federal District, Brazil). Brasília, UnB, 2009.

\begin{tabular}{lcccc}
\hline Hortaliças & FC 1 Abril & FC 1 Maio & FC 1 Junho & FC1 Outubro \\
\hline Alface americana & $1,50 \mathrm{a}^{*}$ & $1,36 \mathrm{a}$ & $1,22 \mathrm{a}$ & $1,33 \mathrm{a}$ \\
Alface roxa & $1,78 \mathrm{a}$ & $1,17 \mathrm{~b}$ & $1,25 \mathrm{~b}$ & $1,60 \mathrm{a}$ \\
Alface lisa & $1,39 \mathrm{a}$ & $1,39 \mathrm{a}$ & $1,24 \mathrm{a}$ & $1,43 \mathrm{a}$ \\
Alface crespa & $1,45 \mathrm{a}$ & $1,45 \mathrm{a}$ & $1,33 \mathrm{a}$ & $1,48 \mathrm{a}$ \\
Acelga & $1,67 \mathrm{a}$ & $2,08 \mathrm{a}$ & $1,38 \mathrm{a}$ & $1,28 \mathrm{~b}$ \\
Agrião & $2,75 \mathrm{a}$ & $2,43 \mathrm{a}$ & $1,80 \mathrm{a}$ & $1,75 \mathrm{a}$ \\
Almeirão & $1,57 \mathrm{a}$ & $1,79 \mathrm{a}$ & $1,50 \mathrm{a}$ & $1,57 \mathrm{a}$ \\
Couve & $1,52 \mathrm{a}$ & $1,60 \mathrm{a}$ & $1,68 \mathrm{a}$ & $1,50 \mathrm{a}$ \\
Chicória & $1,53 \mathrm{a}$ & $1,48 \mathrm{a}$ & $1,35 \mathrm{a}$ & $1,47 \mathrm{a}$ \\
Espinafre & $1,59 \mathrm{a}$ & $1,43 \mathrm{a}$ & $1,70 \mathrm{a}$ & $1,58 \mathrm{a}$ \\
Escarola & $1,36 \mathrm{a}$ & $1,44 \mathrm{a}$ & $1,04 \mathrm{~b}$ & $1,37 \mathrm{a}$ \\
Mostarda & $1,69 \mathrm{a}$ & $2,11 \mathrm{a}$ & $1,46 \mathrm{a}$ & $2,12 \mathrm{a}$ \\
Repolho branco & $1,12 \mathrm{a}$ & $1,12 \mathrm{a}$ & $1,12 \mathrm{a}$ & $1,19 \mathrm{~b}$ \\
Repolho roxo & $1,11 \mathrm{a}$ & $1,13 \mathrm{a}$ & $1,11 \mathrm{a}$ & $1,15 \mathrm{a}$ \\
Rúcula & $2,07 \mathrm{a}$ & $1,71 \mathrm{a}$ & $1,79 \mathrm{a}$ & $1,86 \mathrm{a}$ \\
\hline
\end{tabular}

*Letras iguais na mesma linha indicam que não houve diferença significativa ao nível de $5 \%$ (same letter in the same line indicates no significant difference at 5\%).

menor durante a entressafra $(1,15) \mathrm{em}$ comparação à safra $(1,71)(\mathrm{p}<0,05)$. Tanto para o agrião na safra $(1,77)$ quanto para o espinafre $(1,44)$, não houve diferença com relação ao FC2 quando caracteriza e permite a padronização dos produtos processados. É a partir do conhecimento desses fatores que a unidade pode planejar melhor suas compras, avaliando as hortaliças que apresentam maiores ou menores perdas na safra e na entressafra, bem como o desempenho de seus funcionários na limpeza dessas hortaliças. O mercado já apresenta produtos que não necessitam de limpeza e consequentemente, de descarte de matéria-prima. Entretanto, é importante comparar os custos desses produtos com aqueles que necessitam de limpeza.

A sobrevivência das UANs depende, em grande parte, de processos de avaliação e mensuração das perdas ocorridas. Técnicas que permitam diagnosticar, avaliar e definir a relevância de processos e também as perdas diretas e indiretas devem ser desenvolvidas nessas unidades. Tais técnicas como, determinação de FC, determinação de fatores de cocção, avaliação de degelo, controle de estoque, vão servir de subsídio ao planejamento eficiente e adequado de cardápios e de refeições.

No contexto apresentado é importante destacar a influência do manipulador no FC2, pois nesta fase são retiradas as 
Tabela 3. Fatores de Correção Inicial (FC1) de 15 hortaliças coletadas na Ceasa de Brasíla comparados aos resultados da literatura (comparison among the Initial Correction Factor (FC1) of 15 vegetable crops collected from the CEASA in Brasília, Federal District, Brazil), and the FC1 present in the literature). Brasília, UnB, 2009.

\begin{tabular}{lccc}
\hline Hortaliças & Estudo FC 1 & Ornellas $^{\mathbf{1}} \mathbf{F C ~ 1}$ & Luna $^{\mathbf{2}} \mathbf{F C ~ 1}$ \\
\hline Alface lisa & $1,36 \mathrm{a}^{*}$ & $1,09 \mathrm{~b}$ & $1,53 \mathrm{c}$ \\
Alface crespa & $1,42 \mathrm{a}$ & - & $1,60 \mathrm{c}$ \\
Acelga & $1,60 \mathrm{a}$ & $1,54 \mathrm{a}$ & $1,07 \mathrm{c}$ \\
Agrião & $2,18 \mathrm{a}$ & $1,78 \mathrm{~b}$ & - \\
Almeirão & $1,60 \mathrm{a}$ & - & $1,12 \mathrm{c}$ \\
Couve & $1,58 \mathrm{a}$ & - & $1,68 \mathrm{a}$ \\
Chicória & $1,46 \mathrm{a}$ & $1,40 \mathrm{a}$ & $1,31 \mathrm{a}$ \\
Espinafre & $1,58 \mathrm{a}$ & $1,78 \mathrm{~b}$ & $1,11 \mathrm{c}$ \\
Escarola & $1,30 \mathrm{a}$ & $1,92 \mathrm{~b}$ & $1,50 \mathrm{c}$ \\
Repolho branco & $1,14 \mathrm{a}$ & $1,72 \mathrm{~b}$ & $1,23 \mathrm{c}$ \\
Repolho roxo & $1,13 \mathrm{a}$ & - & $1,11 \mathrm{a}$ \\
Rúcula & $1,86 \mathrm{a}$ & - & $1,57 \mathrm{c}$ \\
\hline
\end{tabular}

${ }^{1}$ Ornellas (2006); ${ }^{2}$ Luna \& Teixeira (1999); ${ }^{*}$ Letras iguais na mesma linha indicam que não houve diferença significativa a nível de $5 \%$ (same letters in the same line indicates no significant difference at 5\%) .

partes que habitualmente são consumidas, mas que dependendo da preparação não são utilizadas, a exemplo dos suflês, que requerem a retirada dos talos que apresentem maior quantidade de fibras e por isso modificam a textura da preparação. É necessário que treinamentos sejam realizados na UAN visando o reaproveitamento das perdas de maneira a minimizar os custos. Um exemplo é o reaproveitamento dos talos do agrião para a produção de bolinhos, ou dos talos de couve na produção de farofas ou de sucos, agregando valor nutritivo às preparações. O profissional responsável pelo planejamento do cardápio deve fazer uma previsão do processo de reaproveitamento de modo que as perdas não sejam consideradas custos para a unidade de processamento.

A comparação de FCs obtidos no presente estudo com resultados disponíveis na literatura (Ornellas, 2006; Luna $\&$ Teixeira, 1999) para o planejamento de cardápios em UAN são apresentados na Tabela 3. Houve diferenças $(p<0,05)$ para alface lisa, alface crespa, acelga, agrião, almeirão, espinafre, escarola, repolho branco, e rúcula. As diferenças percentuais entre os dados desse estudo comparado àqueles obtidos por Ornellas (2006) e Luna \& Teixeira (1999) variam de $7,9 \%$ a $50,9 \%$, ambos para o repolho branco. Diferenças também foram encontradas para acelga (49,5\%), almeirão $(42,9 \%)$, espinafre $(42,3 \%)$ e escarola $(47,7 \%)$.

Ornellas (2006) e Luna \& Teixeira (1999) não descrevem a técnica utilizada no pré-preparo, a habilidade da mão-de-obra, a sazonalidade e a qualidade do produto, que são fatores que influenciam diretamente na determinação do FC. Nesse estudo os fatores habilidade de mão de obra e qualidade do produto também não foram analisados, considerando-se que um único manipulador executou os procedimentos de limpeza.

No estudo conduzido por Ornellas (2006), não foi mencionada como foi realizada a coleta das amostras, se a avaliação foi feita em triplicata ou se a compra das hortaliças foi feita em locais diferentes. A diferença dos resultados apresentados neste estudo em relação aos dos autores citados se deu, em parte, pela ausência de informações em suas pesquisas quanto aos critérios utilizados, tais como manipulação, safra, e partes retiradas das hortaliças. As referidas comparações só podem ser realizadas para estudos acadêmicos como forma de destacar a importância da descrição metodológica para determinação dos FCs e ineditismo do presente estudo.

Diante disso, ressalta-se a importân- cia da realização de estudos de avaliação desses fatores para subsidiar as UANs no preparo de seus cardápios até que essas unidades possam gerar suas próprias informações que possam ser utilizadas em seus planejamentos. Existe desconhecimento por parte do consumidor do que é colhido no campo e comprado pela UAN até a sua utilização na montagem de uma refeição. As perdas variam, dependendo da forma como as hortaliças são transportadas e armazenadas até o local de venda, de quanto tempo permanecem nos estabelecimentos até serem compradas e utilizadas nas residências e estabelecimentos comerciais, bem como na forma de processamento e na habilidade do manipulador.

Ao analisar as diferenças entre os FCs das hortaliças, observa-se que este fator é influenciado pela proximidade da colheita e da comercialização, pelos cuidados dispensados pelo fornecedor, pela adequação do transporte e do armazenamento adequado do alimento. Estes elementos propiciam menores perdas e desperdícios devido à presença de partes amassadas, estragadas ou impróprias para o consumo. Assim, conclui-se que medidas tomadas desde a fase de pós-colheita até o consumo são necessárias para reduzir os FCs e consequentemente, os desperdícios e os custos. Recomenda-se ainda que cada UAN ou residência construa uma tabela de FC, considerando a importância deste fator como indicador de perdas, o qual pode ser influenciado pelos elementos anteriormente citados.

A manutenção da qualidade do produto para consumo in natura não depende unicamente do meio ambiente, do uso de máquinas, de métodos e de matérias-primas adequadas, mas também das técnicas de produção, dos tratos fitossanitários, manuseio pós-colheita, armazenamento e transporte adequados, etc. O ser humano é o elemento central na implantação de sistemas de qualidade em qualquer organização. Desta maneira, todos os indivíduos que compõem a cadeia de processamento das hortaliças precisam ser sensibilizados quanto à adoção de métodos adequados de produção, manipulação no campo, armazenamento, transporte e comercialização dos alimentos. 


\section{REFERÊNCIAS}

AKUTSU RC; BOTELHO RBA; CAMARGO EB; SÁVIO KEO; ARAÚJO WMC. 2005. Adequação das boas práticas de fabricação em serviços de alimentação. Revista Nutrição 18: 419-27.

ARAÚJO WMC; MONTEBELLO NP; BOTELHO RBA. (org) 2007. Alquimia dos alimentos. Brasília: Senac.

BOTELHO RA; CAMARGO EB. 2005. Técnica dietética - Seleção e Preparo de Alimentos Manual de Laboratório. 1a. ed. São Paulo: Atheneu, v. 1. 167p.

BRASIL. IBGE. 2004. Índices de perdas do plantio à pré-colheita dos principais grãos cultivados no País 1996-2002. Brasília: 7 p.

BRASIL. Ministério da Saúde. Agência Nacional Vigilância Sanitária. 2008a. Resolução Comissão Nacional de Normas e Padrões para Alimentos nº 12 , de 24 de julho de 1978. Disponível em: http://www.anvisa.gov.br. Acessado em: 20 jun. 2008a.

BRASIL. Ministério da Agricultura, Pecuária e Abastecimento. Companhia de Entrepostos e Armazéns Gerais de São Paulo. 2008b. Diga não ao Desperdício. Disponível em: http:// www.ceagesp.com.br.

BORGES, R.F. 1991. Panela Furada: o incrível desperdício de alimentos no Brasil. São Paulo: Columbus.

COSTA HS; VASILOPOULOU E; TRICHOPOULOU A; FINGLAS P. 2010. New nutritional data on traditional foods for European food composition databases. European Journal of Clinical Nutrition 64.

GOMES FP. 2000. Curso de estatística experimental. 14 ed. Piracicaba: Degaspari. $477 \mathrm{p}$.

GUIMARÃES FPM; SOUZA G. 2000. Importância do receituário padrão em Fast Service. Revista Nutrição em Pauta 20.

HAIR JF; BLACK WC; BABIN BJ; ANDERSON RE; TATHAM RL. 2009. Análise Multivariada de dados. 6 ed. Porto Alegre: Bookman. 688p.

HIRSCHBRUCH MD. 1998. Unidades de Alimentação e Nutrição: desperdício de alimentos x qualidade da produção. Higiene Alimentar 12: 12-14.

IEA- Instituto de Economia Agrícola. 2005. O papel da logística na cadeia de produção dos hortifrutis. Disponível em: http://www.iea. sp.gov.br. Acessado em 21 de junho de 2008.

LANZILLOTTI HS; MONTE CRV; COSTA VSR; COUTO SRM. 2004. Aplicação de um modelo para avaliar projetos de unidades de alimentação e nutrição. Nutrição Brasil 3: 11-17.

LUNA NMM; TEIXEIRA AB. 1999. Técnica Dietética Fator de Correção em Alimentos de Origem Animal e Vegetal. Cuiabá, 2 ed.

ORNELLAS LH. 2006. Técnica dietética: seleção e preparo de alimentos. 8. ed. São Paulo: Atheneu. 296p.

PERONE M. País do desperdício. 2008. Disponível em: http://redeglobo.globo.com/ cgibin/jornaldaglobo. Acessado em: 20 de março de 2008.

PROENÇA RPC; SOUSA AA; VIEIROS MB; HERING B. 2005. Qualidade nutricional e sensorial na produção de refeições. Nutrição em Pauta 13: 4-16.

TEICHMANN IM. 2000. Tecnologia culinária. Caxias do Sul: EDUCS.

VILELA NJ; LANA MM; MAKISHIMA N. 2003a.O peso da perda de alimentos para a sociedade: o caso das hortaliças. Horticultura Brasileira 21: 141-143.

VILELA NJ; LANA MM; NASCIMENTO EF; MAKISHIMA N. 2003b. Perdas na comercialização de hortaliças em uma rede varejista do Distrito Federal. Cadernos de Ciência e Tecnologia 20: 521-541. 